\title{
HYDROBURST TEST METHODOLOGY FOR EVALUATION OF COMPOSITE STRUCTURES
}

\author{
By: \\ R.C. Thompson \\ T.T. Pak \\ B.M. Rech
}

Fourteenth Symposium on Composite Materials:

Testing and Design (ASTM), March 11-12, 2002, Pittsburgh, PA

PR - 323

Center for Electromechanics

The University of Texas at Austin

PRC, Mail Code R7000

Austin, TX 78712

(512) 471-4496 
Richard C. Thompson, ${ }^{1}$ Tony T. Pak, ${ }^{1}$ and Ben M. Rech $^{1}$

\title{
Hydroburst Test Methodology for Evaluation of Composite Structures
}

\author{
Reference: Thompson, R. C., Pak, T. T., and Rech, B. M., "Hydroburst Test \\ Methodology for Evaluation of Composite Structures," Composite Materials: \\ Testing and Design Fourteenth Volume, ASTM STP 1436, C. E. Bakis, Ed., \\ ASTM International, West Conshohocken, PA, 2003.
}

\begin{abstract}
The University of Texas at Austin Center for Electromechanics (UT-CEM) is under contract to develop high-speed composite flywheel systems for a number of energy and power averaging applications in the transportation and space industries. Safe and reliable design of composite flywheels requires well-characterized material properties. Efforts have been focused on design optimization of a hydroburst test technique that demonstrates a useful method for characterizing the hoop (circumferential) properties of filament wound composite rings, and those results are then available to predict the performance of full-scale flywheels.

To demonstrate the usefulness of this method, this paper discusses typical hydroburst techniques to determine material properties for filament-wound composite rings. Test results are also presented. Seal design is a key element of this fixture, and a design has evolved that provides nearly uniform radial loading on the inside surface of the composite ring, while minimizing axial bending. Correlations of tow strand data with hydroburst lamina data are presented. Also discussed are hydroburst test applications for flaw assessment and fatigue property evaluation.
\end{abstract}

Keywords: hydroburst, composites, material properties, filament winding

\section{Hydroburst Methodology}

\section{Overview}

The University of Texas at Austin-Center for Electromechanics (UT-CEM) is currently under contract to develop composite flywheel energy storage systems in the transportation and space industries. Shown in Fig. 1 is the flywheel design developed by UT-CEM, to be used in a hybrid electric transit bus. The energy storage potential of a flywheel is proportional to its mass polar moment of inertia and the square of the rotational speed. Specific energy (stored kinetic energy/system mass) is limited by the strength-to-density ratio of the material; for this reason, high strength composite materials are the preferred flywheel material.

For safe operation of these rotating composite structures, a reliable and cost-effective test technique is needed to generate a statistically significant population of critical thermo-mechanical properties. The hydroburst test method attempts to address this need.

\footnotetext{
${ }^{1}$ Center for Electromechanics, MC R7000, The University of Texas at Austin, Austin, TX 78712.
} 
Limited published literature, which describes the fixture design and presents measured hydroburst data, is available [1,2]. Discussed here is our test methodology that provides flexibility for both static and cyclic hoop tests, under representative service temperatures.

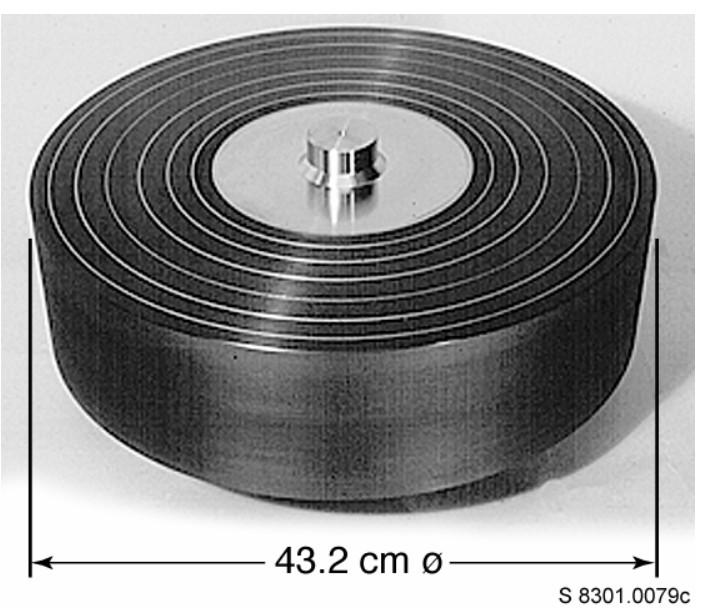

Fig. 1 - Composite flywheel for a Houston Metro transit bus; diameter $43.16 \mathrm{~cm}$; length $12.71 \mathrm{~cm}$; tip speed $900 \mathrm{~m} / \mathrm{s}$ at $40000 \mathrm{rpm}$

\section{Test Fixture Description}

Simply, for the hydroburst test approach, hoop loading of a composite ring is accomplished by pressurizing the inside surface of a hydroburst seal, which then induces hoop strains into the composite specimen. The fixture consists of upper and lower steel plates, a steel spacer plate, and a high-elongation seal. A cross-section is illustrated in Fig. 2.

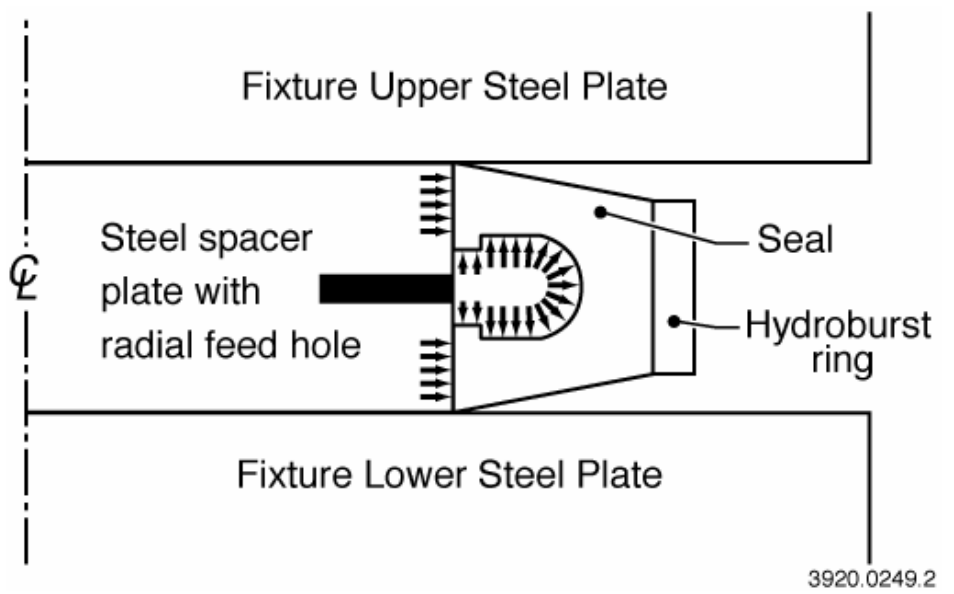

Fig. 2 - Cross-section of hydroburst fixture with a notional seal profile 
An assembly drawing, as well as a detailed drawing of the seal, is presented in the appendix. In hydroburst testing, a thin section of the filament wound structure (Fig. 3) serves as the flexible element of a variable volume pressure vessel. When fluid is pumped though the radial feed hole in the steel spacer plate (which pressurizes the inside surface of the seal) hoop tensile stresses are developed in the test ring as the radial pressure of the seal loads the inside surface of the test ring. Integrated 2,500 W, $480 \mathrm{~V}$ heating elements permit elevated temperature testing up to $177^{\circ} \mathrm{C}$. These band heaters are clamped to the outside surface of the lower and upper steel plates.

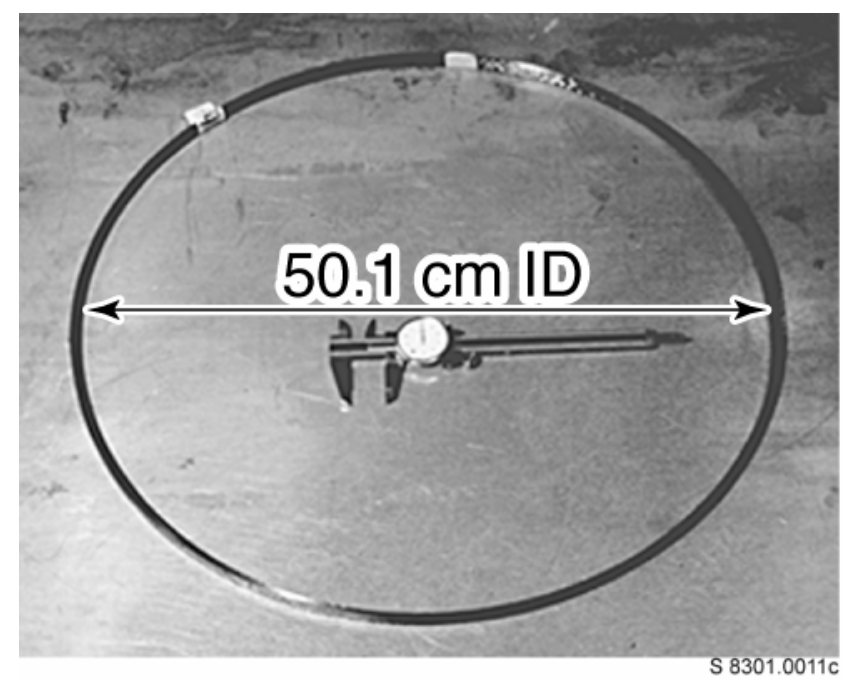

Fig. 3 - Typical hydroburst composite ring

The hydroburst fixture is preloaded inside a hydraulic press (Fig. 4). Since the fixture is void of bolted interfaces, less test time is involved with installation and removal of the test specimen. Also, data generation (the amount needed for statistical purposes) can be achieved in a more timely manner. Typical ultimate tensile strength/strain (UTS) tests, at room temperature and with instrumented coupons, can be completed at the rate of over ten per hour. Elevated temperature tests require more time since the coupon and surrounding test structure must re-attain the test temperature.

Also, the modular features of the fixture permit testing of composite rings of various dimensions. Changing the spacer plate and seal dimensions can accommodate composite specimens of different diameters and lengths.

\section{Hydroburst Seal Design}

The seal material is a modified Teflon ${ }^{\circledR}$ (polytetrafluoroethylene) material. The modification is proprietary to the seal manufacturer, and this seal design can be obtained directly from TEI Sealing Systems (see Appendix). 


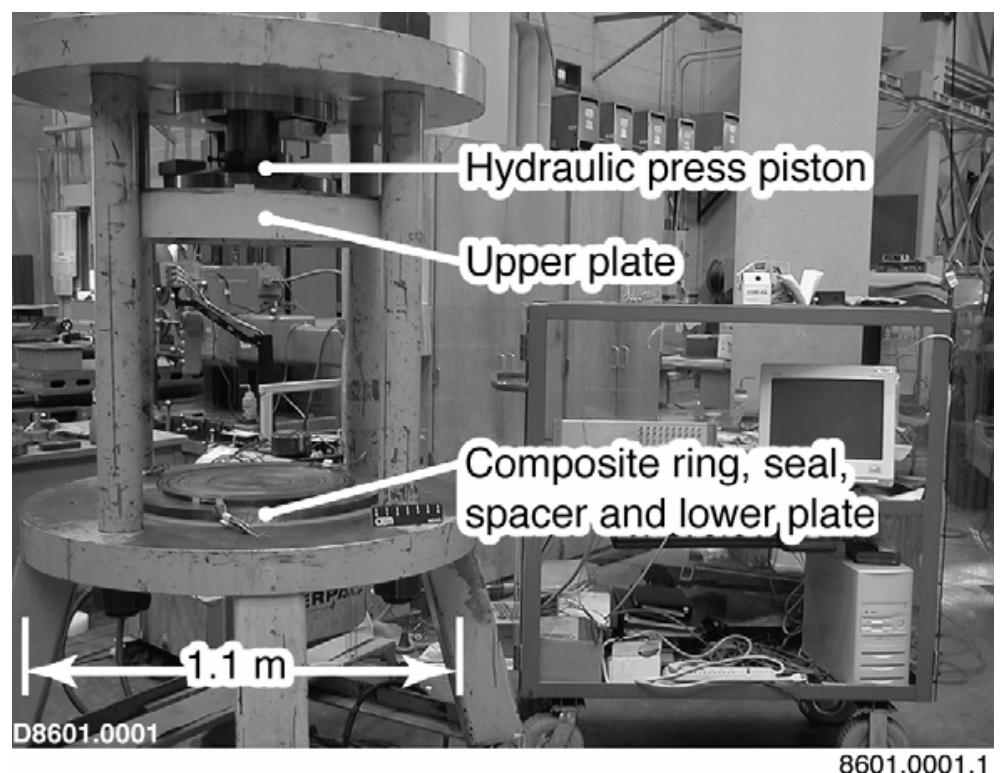

Fig. 4 - Hydroburst fixture mounted inside the press assembly

The hydroburst seal is a key element of this fixture, and a design has evolved that provides near uniform radial loading on the inside surface of the composite ring. Early seal designs possessed large frictional forces at the upper and lower steel plate interfaces. This friction, acting to restrain the end faces of the seal from outward radial growth while the internal pressure outwardly displaces the center section, forces convex curvature of the outer surface. This convex curvature results in a maximum outward bulge at the midplane of the seal, with the surface tapering radially toward the end faces. The distorted shape, driven by the large internal pressures, applies a non-uniform radial load on the composite test specimen in the axial direction, inducing axial strains in the composite ring due to axial bending. Our current seal design, however, has reduced axial bending by almost a factor of five compared to past seal designs, with typical tensile axial strain values (measured with axially oriented strain gauges on the outer surface of the ring) in the range of about $0.05 \%$, depending upon the flexural modulus of the ring for this type of compliance.

The seal design drawing is shown in the appendix (Fig. A-2). As shown in the figure, dual circumferential grooves, located on the inside surface, responding to the internal pressurization, force the end faces of the seal to expand against the steel plates. This action helps the seal to contain the working fluid and maintain pressure. The end faces are flared outward slightly, which preloads these areas of the seal with the steel plates at assembly. This feature serves to provide initial sealing until the seal cavity is pressurized.

To avoid possible data degradation on critical test programs, a new seal is used for each UTS hydroburst test. However, a tested seal usually does not experience gross structural failure, but the material will yield leading to elongation in the hoop direction. For less critical test programs, such as screening exercises, the seal may be reused for up to five hydroburst tests. 


\section{Composite Ring Test Specimens}

For current tooling, test ring specifications are $51.0 \mathrm{~cm} \pm 0.191 \mathrm{~cm}$ for the inside diameter, $1.23 \mathrm{~cm} \pm 0.013$ on the axial length, and a range of about $0.127 \mathrm{~cm}$ to $0.64 \mathrm{~cm}$ for thickness. However, as discussed earlier, different specimen axial length and thickness can be tested, with minor fixture changes. Obtainable seal fluid pressure is primarily dependent on hydraulic press capability, which must overcome the vertical force generated within the seal cavity. For a 1.8 MN hydraulic press, obtainable seal pressure is $45 \mathrm{MPa}$; however, greater press loads would permit a seal pressure to $70 \mathrm{MN}$. No requirement is stated for circularity or cylindricity, since this is more a function of winding mandrel and composite fabrication process.

Ring fabrication can originate with a number of processes, but examples shown in this paper utilized the filament winding approach using $12 \mathrm{~K}$ carbon fiber tow preimpregnated with an RS-3 cyanate ester resin manufactured by YLA, Inc. Typical towpreg bandwidth was $3.18 \mathrm{~mm}$, and the composite rings were fabricated using a single tow laydown. Processing procedures unique to cyanate ester resins were followed (mainly a nitrogen purge of the autoclave to minimize moisture content within the autoclave during cure [3]).

\section{Typical Test Procedure}

Both hoop and axially oriented strain gauges are bonded to the outer surface of the composite ring. During seal pressurization, strain gauge and seal pressure data are digitally recorded. Three to six hoop strain gauges and two to four axial strain gauges are installed per ring. Shown in Fig. 5 is a typical strain response. Hoop lamina strength can be directly obtained using the thin-walled cylinder relationship, as discussed below. If fiber volume (FV) of the lamina can be obtained (e.g., acid digestion), the modulus derived from the FV and dry fiber properties can also be used to calculate lamina strength using Hooke's law, $\sigma_{\theta}=E_{\theta} \varepsilon_{\theta}$, where $\theta$ refers to the hoop direction. Poisson effects are ignored, which is valid when the hoop modulus dominates the structural response. In the figure, it can be seen that loading of the composite test specimen produces a linear hoop strain response. The near-zero dwell in strain response, at the beginning of pressurization event, is due to a combination of seal surface-to-composite ring makeup and the frictional effects of the seal discussed earlier. The pressure point associated with the initial strain response, occurring at about $1,100 \mathrm{kPa}$, is subtracted from the recorded seal pressure at failure, for composite ring strength calculation.

For an idealized case where a similar composite test ring is subjected only to internal pressurization (i.e., no forced edge effects), the global axial strain of the ring versus its load would start at zero and then progress linearly toward some compressive strain value, whose final value would depend upon the mechanical properties of the composite. This behavior is seen in the figure with an axial compressive strain of about $0.4 \%$ at the point of failure. At the beginning of the test, however, the seal effects (see Hydroburst Seal Design) superimpose tensile strain from a slight bending of the composite in the axial direction which is measured by the axially oriented strain gauge $(0.0536 \%$ at about 1.4 MPa for the case in Fig. 5). 


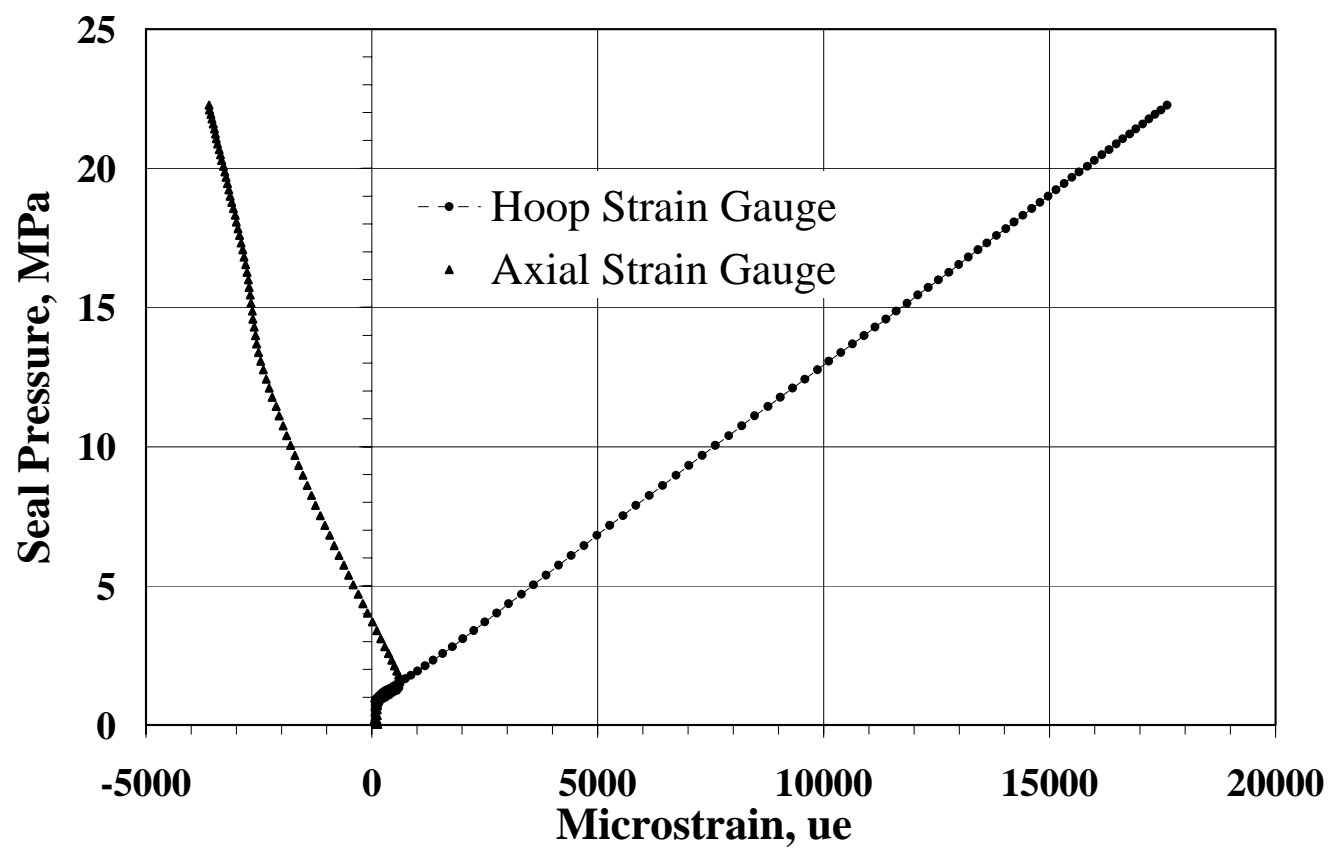

Fig. 5 - Typical strain variations from the hydroburst test of a composite ring

\section{Thin-walled cylinder approach}

The peak hoop lamina strength can be estimated using the thin-wall cylinder relationship for cases where the wall thickness of the ring is very small compared to its diameter [4]:

$$
\sigma_{\theta}=\frac{P D}{2 t}
$$

where

$$
\begin{aligned}
\sigma_{\theta} & =\text { peak hoop strength } \\
P & =\text { seal pressure adjusted for seal effects } \\
D & =\text { strain }- \text { adjusted, mean diameter of the ring } \\
t & =\text { averagering thickness }
\end{aligned}
$$

When applying this approach, care must be used to understand that as the $t / D$ ratio increases, the maximum hoop stress at the inner surface of the ring and minimum hoop stress occurring at its outer surface will diverge and become significantly different values. Hoop strain responds similarly.

For the cases presented here, the $t / D$ ratios are 0.005 or less. Also, as suggested in Juvinall [4], using the mean diameter (as opposed to the inside diameter) provides a good approximation for maximum hoop stress for very small $t / D$ ratios. For the $t / D$ ratio of 0.005 , equation (1) provides an accurate value for the maximum hoop stress at the bore of the ring (within $0.002 \%$ of the value from the more general thick-wall cylinder equation). 


\section{Material design allowables}

Statistical properties can be calculated from an appropriate number of individual ring specimens. The number of samples depends upon the behavior of the data as well as the program requirements for the intended application. The hydroburst fixture provides a means to generate the large number of samples necessary to determine A-basis and B-basis type design allowables, within a reasonable time and cost. UT-CEM uses the guidelines set forth in MIL-HDBK-17 [5] for generation and interpretation of the statistical hydroburst data for design purposes.

\section{Other test applications}

The hydroburst test method is used for other composite evaluations besides UTS measurements. As shown in Table 1, on past flywheel programs, UT-CEM has preconditioned composite rings with intentional flaws, to evaluate performance degradation. This work was performed for NASA Glenn Research Center for a flywheel energy storage system program for the International Space Station. The intent was to introduce possible material flaws that may contaminate the structure during fabrication. Flaws included bagging materials and forced delaminations by the inclusion of Teflon ${ }^{\circledR}$ tape. The first two ring lots in Table 1 did not include intentional flaws. Testing showed that the flaws contained in the last two ring lots, at least to the extent of this preliminary effort, did not show appreciable differences in strain at failure.

Table 1 - Example of hydroburst testing to evaluate the effects of flaws from foreign materials on hoop lamina strength

\begin{tabular}{lccc}
\hline \multicolumn{4}{l}{ Room Temperature Strain-To-Failure Test Results for IM7/8552 Lamina } \\
\hline Ring Lot \# & \# of Rings Tested & Mean (\% strain) & Std Dev (\% strain) \\
\hline HB 1.1 & 5 & 1.31 & 0.06 \\
HB 1.2 & 5 & 1.28 & 0.04 \\
HB 1.3* & 5 & 1.33 & 0.06 \\
HB 1.4** & 5 & 1.28 & 0.05 \\
\hline
\end{tabular}

* intentional foreign material flaws

** intentional delamination over $50 \%$ of circumference

UT-CEM has also used the hydroburst method for evaluating cumulative damage from cyclic loading at elevated temperature. For fatigue tests, an oscillating pressure source cycles the seal pressure between two set points, resulting in a load-controlled approach. The pressure oscillations induce strain oscillations as shown in Fig. 6. Under the NASA Glenn Research Center flywheel program for the International Space Station, composite rings were cycled at UT-CEM at an elevated temperature of $93^{\circ} \mathrm{C}$, to at least 375,000 cycles each. Following the cyclic loading, the rings were re-instrumented with strain gauges, then hydroburst tested to failure to determine tensile strain-to-failure, as shown in Table 2. 


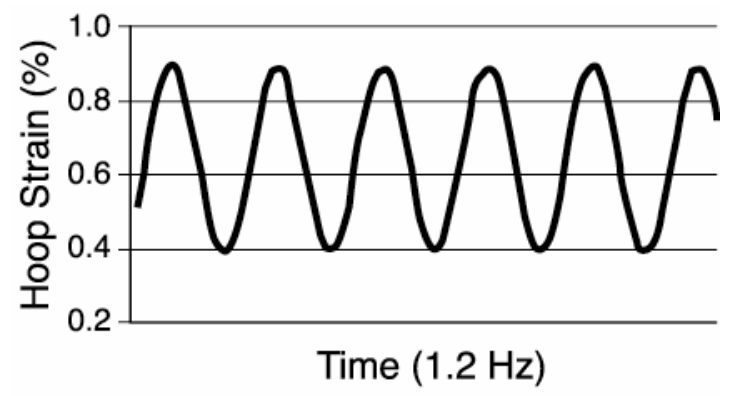

Fig. 6 - Cyclic loading of a composite ring for a flywheel application

The durability of the hydroburst seal is a critical design feature that allows thousands of cyclic tests at elevated strain states and temperature without pressure loss or other perturbations that may interfere with the experiment.

\section{Test Results and Discussion: Comparison of Hydroburst Data with Tow Strand Data}

The structural design engineer typically desires to perform limited coupon-level testing to arrive at a set of design allowables. A useful approach for screening new materials is to perform simple tow strand tests to obtain tow properties. These tests would then be followed by a limited but appropriate number of hydroburst lamina tests, for verification and generation of a design allowable database. To demonstrate this approach, the following discussion presents measured tow strand data, hydroburst data, and comparison of the two. All tests were performed at room temperature.

Generation of the tow strand data is discussed next, followed by a discussion of the hydroburst specimen data. The same two materials were evaluated for both the tow strand data and hydroburst data.

Table 2 - Ultimate strain data following cyclic fatigue using the hydroburst method at near room and elevated temperatures

\begin{tabular}{|c|c|c|c|}
\hline \multirow[b]{2}{*}{ Ring \# } & \multicolumn{3}{|c|}{ Ultimate Strain To } \\
\hline & \# of Cycles & Failure (\%) & Temperature $\left({ }^{\circ} \mathrm{C}\right)$ \\
\hline HB 1.2.2 & 480,000 & 1.25 & 27 to 32 \\
\hline HB 1.2.10 & 375,000 & 1.28 & 27 to 32 \\
\hline HB 1.2.11 & 375,000 & 1.25 & 27 to 32 \\
\hline HB 1.3.8 & 375,000 & 1.41 & 27 to 32 \\
\hline HB 1.2.12 & 375,000 & 1.12 & 93 to 96 \\
\hline HB 1.2.13 & 375,000 & 1.25 & 93 to 96 \\
\hline
\end{tabular}

Tow Strand Data

The tow strand tests for two different carbon fibers, sized IM9 (Hexcel) and sized T1000G (Toray) impregnated with cyanate ester resin RS-3 (YLA), were performed to obtain fiber strength. Towpreg was wound onto a flat mandrel and autoclave-cured. Bagging prior to cure was done in a manner to minimize resin bleed. Straight, individual tow specimens were then tabbed (resulting in a gauge section length of about $25.4 \mathrm{~cm}$ ) and then loaded to failure in a tensile test fixture. Shown in Table 3 is fiber strength, 
based upon yield and density values provided by the fiber suppliers to determine total fiber cross-sectional area. The presence of sizing was not accounted for in the area calculation. Test procedures were guided by ASTM D4018-93, "Test Methods for Properties of Continuous Filament Carbon and Graphite Tows," and procedures used by the Army Research Laboratories [6].

Table 3 - Fiber strength data from tow strand tests

\begin{tabular}{lcc}
\hline Tow Strand & $\begin{array}{c}\text { Calculated Fiber } \\
\text { Strength Mean } \\
\text { at Failure (MPa) }\end{array}$ & $\begin{array}{c}\text { Calculated Fiber } \\
\text { Strength Standard } \\
\text { Deviation at } \\
\text { Failure (MPa) }\end{array}$ \\
\hline IM9/RS-3 & 5,509 & 402 \\
T1000G/RS-3 & 5,851 & 421 \\
\hline
\end{tabular}

Testing performed at Army Research Laboratory, Aberdeen Proving Ground

Correlation of tow lamina strain with hydroburst lamina strain is recognized as a more direct approach, avoiding the cumulative errors associated with stress calculations. Tow strand strain data were not recovered accurately during the test, and are not presented. For accurate strain measurements, extensometers or strain gauges are needed, which avoids possible errors associated with gauge length definition. The tow strand and hydroburst data comparisons presented in this paper are stress-based. The modulus of the fiber of the tow strand is not derived from stress/strain curves, but from the certification documents provided by the supplier. Statistical data in Table 3 are based upon 12 individual tow tests. The IM9/RS-3 strand data contained one obvious outlier ( $40 \%$ deviation off the mean) that was removed from the data.

\section{Hydroburst specimen data}

A long hydroburst ring, about $30 \mathrm{~cm}$ in length, was filament wound onto a steel mandrel and autoclave cured, using a zero bleed bagging procedure. Shown in Table 4 is a description of materials. Hydroburst rings 1 and 2 were all hoop wound.

Table 4 - Description of tow-preg materials and ring fabrication for the hydroburst specimens

\begin{tabular}{|c|c|c|c|c|}
\hline & Tow-Preg Material & Fiber & Resin & Ring Fabrication \\
\hline 1 & IM9/RS-3 & $\begin{array}{l}\text { Hexcel IM9 } \\
\text { (1\% sizing) }\end{array}$ & $\begin{array}{l}\text { YLA RS-3 } \\
\text { cyanate ester }\end{array}$ & All $90^{\circ}$ \\
\hline 2 & T1000G/RS-3 & $\begin{array}{c}\text { T1000G } \\
\text { (0.8\% sizing) }\end{array}$ & $\begin{array}{l}\text { YLA RS-3 } \\
\text { cyanate ester }\end{array}$ & All $90^{\circ}$ \\
\hline
\end{tabular}

The $30 \mathrm{~cm}$ long hydroburst ring was sectioned into individual hydroburst specimens using diamond cutoff tooling on the winding mandrel in a lathe. On one of the sectioned hydroburst specimens, hoop residual strain was measured using a ring sectioning method. 
An alternate method in use for determining hoop residual stress, and strain, is based upon measured springback data from which a residual moment is calculated [7]. The method described below (and used to derive the data presented herein) has the advantage of providing a direct measurement of hoop residual strain at the inside and outside surfaces of the hydroburst ring.

Both inside and outside diameter hoop strain gauges were installed on the ring at diametrically opposed locations. Using diamond cutoff tooling, the ring was sectioned on either side of the hoop gauge sets; the strain-release progression, as the specimen is sectioned, is shown in Fig. 7. Of particular importance is the inside diameter residual tensile strain (far right value for "HOOP 12ID” and "HOOP6ID”) induced by a combination of tow tension, mandrel expansion, and curing. (Note that a compressive strain, after sectioning, indicates a hoop tensile residual strain in the unsectioned specimen.) Residual strain is accounted for in the tow strand vs. hydroburst strength comparisons discussed later. Remaining ring sections from the residual strain tests were then used to determine the FV of the hydroburst ring by acid digestion.

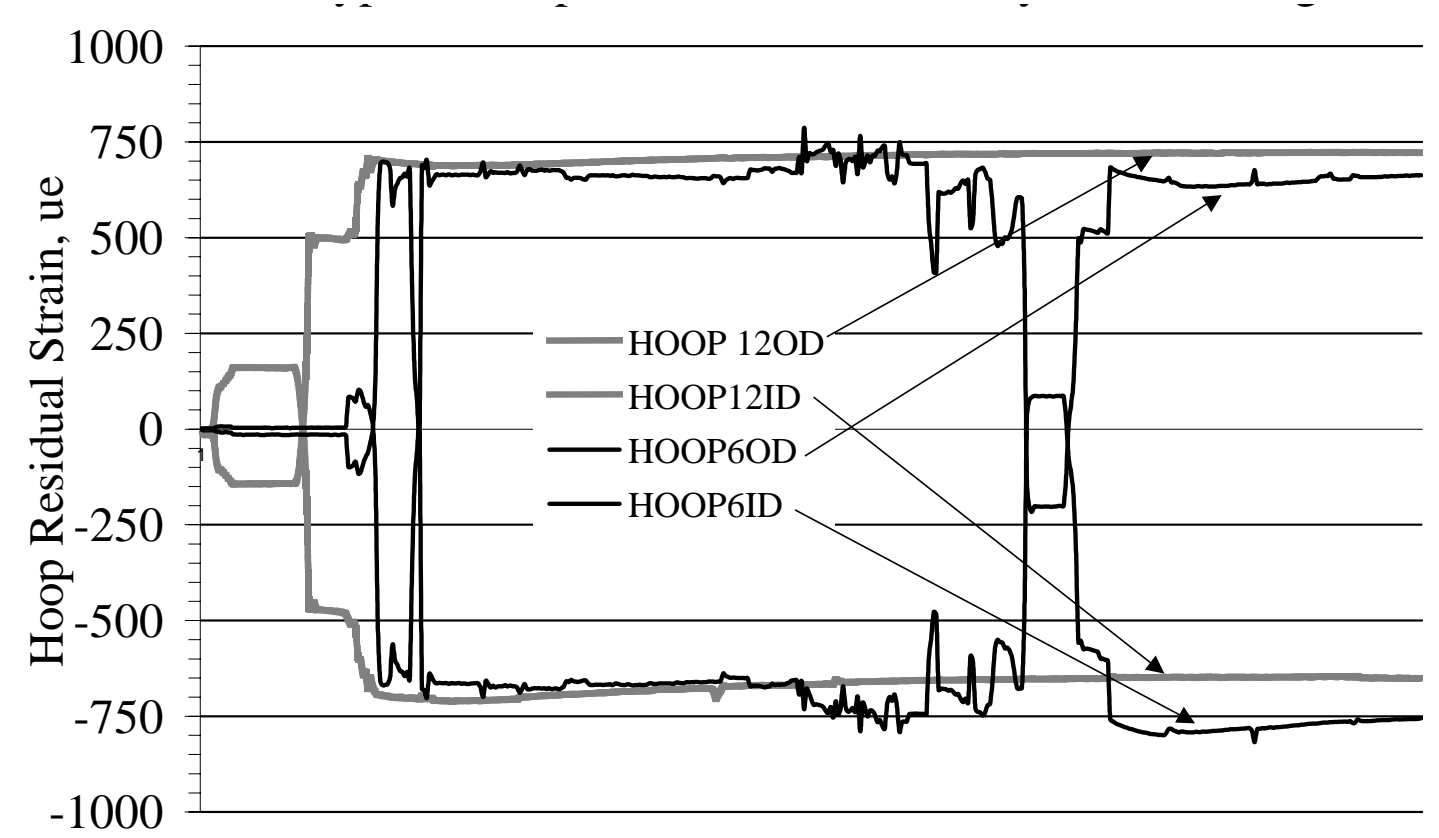

Fig. 7 - Hoop residual strain for typical hydroburst specimen; hoop oriented strain gauges (note "12OD" denotes 12 o'clock orientation, outside diameter gauge, etc.)

Eight hydroburst specimens for each material were tested at room temperature to generate hydroburst lamina data, and are presented in tables 5 and 6. Shown in the first half of each table are measurements from the hydroburst test. Peak hoop stress was calculated using the relationship in equation (1). The seal pressure shown in the tables is an adjusted value obtained by subtracting the pressure associated with the initial strain dwell (see Test Procedure) from the pressure at specimen failure. Subtracted pressure was about 1,100 kPa, but varies slightly with different specimens. Tangent modulus, using a sliding average, was calculated from the resulting stress/strain curve, with 
measured strain recovered from the gauged outer ring surface and stress calculated from $P D / 2 t$. Relevant measured strain values are also shown.

The second half of each table shows predicted UTS and moduli for comparison against the measured values from $P D / 2 t$ in the top half of the table. Hoop moduli were calculated using $E_{\theta}=V_{f} E_{f}$, where $V_{f}$ is the FV of the hydroburst ring determined by acid digestion and $E_{f}$ is fiber modulus from the lot certification of the supplier. The hoop UTS was calculated using Hooke's law, $\sigma_{\theta}=E_{\theta} \varepsilon_{\theta}$, where $\varepsilon_{\theta}$ is the measured hoop strain at failure. The purpose of this exercise is to provide a check against hoop UTS values derived from the thin-wall stress equation. As shown in the tables, UTS for these two approaches, agree within about 6\%.

Hoop residual forces act to reduce the full strength potential of the hydroburst ring (i.e., strength without hoop residuals), resulting in the apparent hoop strength determined by the UTS methods ( $P D / 2 t$ and Hooke's law) discussed above. As seen in the next discussion, the measured hoop tensile residual strain $\varepsilon_{r}$ must be added to $\varepsilon_{\theta}$ for an appropriate comparison of hoop UTS (using the Hooke's law method) with tow strand UTS. The measured value for $\varepsilon_{r}$ is listed in Tables 5 and 6: line \#7.

\section{Tow strand lamina and hydroburst lamina results}

Table 7 presents a comparison of tow strand and hydroburst strength for the IM9/RS3 and T1000G/RS-3 materials. In the table, the fiber strength, derived from the strand test and normalized to the FV of the hydroburst ring, is used to predict the failure strength of the hydroburst specimens. A similar approach is used for comparing moduli, between the tow strand and hydroburst data, shown in Table 8.

Data for the IM9/RS-3 material shows a $13 \%$ and $4 \%$ reduction from the strand strength for the two hydroburst strengths calculated from $P D / 2 t$ and $\sigma_{\theta}=E_{\theta}\left(\varepsilon_{\theta}+\varepsilon_{r}\right)$, respectively. In this case, for the strength calculated by Hooke's law, the residual strain $\left(\varepsilon_{r}\right)$ is added to the measured hoop strain at failure, which assumes that the residual strain in the tow strand samples is insignificant. The T1000G/RS-3 material shows a $20 \%$ and $12 \%$ knockdown for the same data. Generally accepted in the community is a reduction of tow strength, from strand to hydroburst fabrications, and is sometimes referred to as strength translational efficiency. Residual strain will reduce further the strength translational efficiency, and result in reduced apparent strength of hydroburst ring samples.

As is normally the case, the moduli showed good translation between the strand and hydroburst data, and are within about $2.5 \%$ percent of the supplier's certified data.

\section{Conclusion}

The success of UT-CEM with the hydroburst test technique has demonstrated a reliable method for characterizing filament-wound composite rings, which can then be used for performance prediction of flywheels and other similar structures. Several methods were presented here for calculation of the hoop properties of rings from hydroburst tests, with good agreement ( 5\% to 6\%) between these different approaches. 
Table 5 - Hydroburst lamina data for IM9/RS-3

\begin{tabular}{|c|c|c|c|}
\hline \# & Description & Mean & $\begin{array}{l}\text { Standard } \\
\text { Deviation }\end{array}$ \\
\hline 1 & Seal's adjusted fluid pressure at ring failure (MPa) & 32.23 & 0.64 \\
\hline 2 & Hydroburst ring inside diameter (cm) & 51.02 & 0.00517 \\
\hline 3 & Hydroburst ring thickness (cm) & 0.254 & 0.00180 \\
\hline 4 & Hoop UTS, $P D / 2 t(\mathrm{MPa})$ & 3,310 & 78 \\
\hline 5 & Measured hoop strain at failure (\%) & 1.73 & 0.0260 \\
\hline 6 & Measured axial strain at failure (\%) & -0.470 & \\
\hline 7 & Measured hoop residual strain at inside diameter (\%) & 0.088 & \\
\hline 8 & Hoop modulus from hydroburst stress/strain curve (GPa) & 206 & 7.70 \\
\hline 9 & FV of carbon fiber lamina from acid digestion (\%) & 69.2 & 1.23 \\
\hline 10 & Fiber modulus from supplier's lot certification sheet (GPa) & 291 & \\
\hline 11 & Hoop modulus from FV: \#9 x \#10 (GPa) & 201 & \\
\hline 12 & Hoop UTS: \#11 x \#5 (MPa) & 3,482 & 52 \\
\hline \multirow[t]{2}{*}{13} & Hoop UTS + hoop residual strain: \#11 x (\#5 + \#7) (MPa) & 3,658 & 52 \\
\hline & Difference in hoop UTS calculation, \#4 vs. \#12 (\%) & 5.2 & \\
\hline
\end{tabular}

Table 6 - Hydroburst lamina data for T1000G/RS-3

\begin{tabular}{|c|c|c|c|}
\hline \# & Description & Mean & $\begin{array}{l}\text { Standard } \\
\text { Deviation }\end{array}$ \\
\hline 1 & Seal's adjusted fluid pressure at ring failure (MPa) & 29.26 & 1.15 \\
\hline 2 & Hydroburst ring inside diameter $(\mathrm{cm})$ & 51.05 & 0.00779 \\
\hline 3 & Hydroburst ring thickness $(\mathrm{cm})$ & 0.238 & 0.00469 \\
\hline 4 & Hoop UTS, $P D / 2 t(\mathrm{MPa})$ & 3,204 & 125 \\
\hline 5 & Measured hoop strain at failure (\%) & 1.680 & 0.052 \\
\hline 6 & Measured axial strain at failure (\%) & -0.480 & \\
\hline 7 & Measured hoop residual strain at inside diameter (\%) & 0.046 & \\
\hline 8 & Hoop modulus from hydroburst stress/strain curve (GPa) & 199 & 7 \\
\hline 9 & FV of carbon fiber lamina from acid digestion (\%) & 68.14 & 1.12 \\
\hline 10 & Fiber modulus from supplier's lot certification sheet (GPa) & 297 & \\
\hline 11 & Hoop modulus from FV: \#9 x \#10 (GPa) & 202 & \\
\hline 12 & Hoop UTS: \#11 x \#5 (MPa) & 3,402 & 106 \\
\hline \multirow[t]{2}{*}{13} & Hoop UTS + hoop residual strain: \#11 x $(\# 5+\# 7)(\mathrm{MPa})$ & 3,495 & 106 \\
\hline & Difference in hoop UTS calculation, \#4 vs. \#12 (\%) & 6.2 & \\
\hline
\end{tabular}


Table 7 - Comparison of tow strand and hydroburst strength data

\begin{tabular}{|c|c|c|}
\hline Item & $\begin{array}{l}\text { Strength } \\
(\mathrm{MPa})\end{array}$ & $\begin{array}{l}\text { Difference with } \\
\text { towstrand data (\%) }\end{array}$ \\
\hline \multicolumn{3}{|l|}{ IM9/RS-3 } \\
\hline $\begin{array}{l}\text { Predicted hydroburst specimen hoop strength from FV } \\
\text { adjusted strand data (Table } 3 \text { and Table5: \#9) }\end{array}$ & 3,813 & \\
\hline $\begin{array}{l}\text { Hydroburst specimen hoop strength calculated from } \\
\text { PD/2t (Table 5: \#4) }\end{array}$ & 3,310 & -13.2 \\
\hline $\begin{array}{l}\text { Hydroburst specimen hoop strength calculated from } \\
\text { Hooke's law, with the added residual tensile strain } \\
\text { (Table 5: \#13) }\end{array}$ & 3,658 & -4.07 \\
\hline \multicolumn{3}{|l|}{ T1000G/RS-3 } \\
\hline $\begin{array}{l}\text { Predicted hydroburst specimen hoop strength from FV } \\
\text { adjusted strand data (Table } 3 \text { and Table 6: \# 9) }\end{array}$ & 3,987 & \\
\hline $\begin{array}{l}\text { Hydroburst specimen hoop strength calculated from } \\
\text { PD/2t (Table 6: \#4) }\end{array}$ & 3,204 & -19.6 \\
\hline $\begin{array}{l}\text { Hydroburst specimen hoop strength calculated from } \\
\text { Hooke’s law, with the added residual tensile strain } \\
\text { (Table 6: \#13) }\end{array}$ & 3,495 & -12.3 \\
\hline \multicolumn{3}{|c|}{ Table 8 - Comparison of tow strand and hydroburst moduli data } \\
\hline Item & $\begin{array}{l}\text { Modulus } \\
\text { (GPa) }\end{array}$ & $\begin{array}{l}\text { Difference with } \\
\text { towstrand data (\%) }\end{array}$ \\
\hline \multicolumn{3}{|l|}{ IM9/RS-3 } \\
\hline $\begin{array}{l}\text { Predicted hydroburst specimen hoop modulus from } \\
\text { FV adjusted strand data (Table 5: \#11) }\end{array}$ & 201 & \\
\hline $\begin{array}{l}\text { Hydroburst specimen hoop modulus calculated from } \\
\text { hydroburststress/strain curve (Table 5: \#8) }\end{array}$ & 206 & +2.5 \\
\hline \multicolumn{3}{|l|}{ T1000G/RS-3 } \\
\hline $\begin{array}{l}\text { Predicted hydroburst specimen hoop modulus from } \\
\text { FV adjusted strand data (Table 6: \# 11) }\end{array}$ & 202 & \\
\hline $\begin{array}{l}\text { Hydroburst specimen hoop modulus calculated from } \\
\text { hydroburst stress/strain curve (Table 6: \#8) }\end{array}$ & 199 & -1.5 \\
\hline
\end{tabular}

A strength reduction of $4 \%$ to $12 \%$ was observed between tow and hydroburst UTS using Hooke's law adjusted for residual strain, with good translation of moduli. Strength calculated from the thin-walled stress equation showed a $13 \%$ to $20 \%$ reduction compared to the tow data.

Axial tensile strains measured on the outer surface of the ring, appearing only during the initial pressurization, were noted to be on the level of about $0.05 \%$. Although the current seal design has greatly reduced the induced axial strains seen in the past, UTCEM is investigating seal design changes to further reduce this effect. 
A more complete comparison of tow strand and hydroburst data can be achieved if tow strand strain data are recovered, either through the use of extensometers or strain gauges. UT-CEM intends to obtain these data for future similar tests.

\section{Acknowledgment}

The tow and hydroburst data presented in this paper were performed under funding from the Lockheed Martin Electric Gun Program sponsored by the U.S. Army. The impregnated tow strand tests were performed at the Army Research Laboratory at Aberdeen Proving Ground. The authors are grateful for the permission to present and discuss these data.

\section{References}

[1] Etemad, M. R., Pask, E., and Besant, C. B., "Hoop Strength Characterization of High Strength Carbon Fibre Composites," Composites, vol. 23, No. 4, July, 1992.

[2] Cohen, D., Toombes, Y .T., Johnson, A. K., and Hansen, M. F., "Pressurized Ring Test for Composite Pressure Vessel Hoop Strength and Stiffness Evaluation,” ASTM Journal of Composites Technology and Research, October 1995, pp 331-340.

[3] Frame, B.J., “Characterization and Process Development of Cyanate Ester Resin Composites," Technical Report Number ORNL/CP-1-1112, Oak Ridge National Laboratory, Engineering Technology Division, Oak Ridge, Tennessee, March, 1999.

[4] Juvinall, R. C., "Engineering Considerations of Stress, Strain, and Strength,” McGraw-Hill Series in Mechanical Engineering, McGraw-Hill Book Company, New York, NY, 1967.

[5] MIL-HDBK-17-1E, ”Polymer Matrix Composites,” Department of Defense Handbook.

[6] Nguyen, S. P., Ghiorse, L. L., and Mulkern, T. J., “A Survey of Current HighPerformance Carbon Fiber Characterization Methods,” Technical Report Number ARL-TR-2293, Army Research Laboratory/Weapons and Materials Research Directorate, Aberdeen Proving Ground, MD, August, 2000.

[7] Cohen, D., "Influence of Filament Winding Parameters on Composite Vessel Quality and Strength," Composites Part A 28A, p1035 - 1047, July, 1997. 


\section{Appendix}

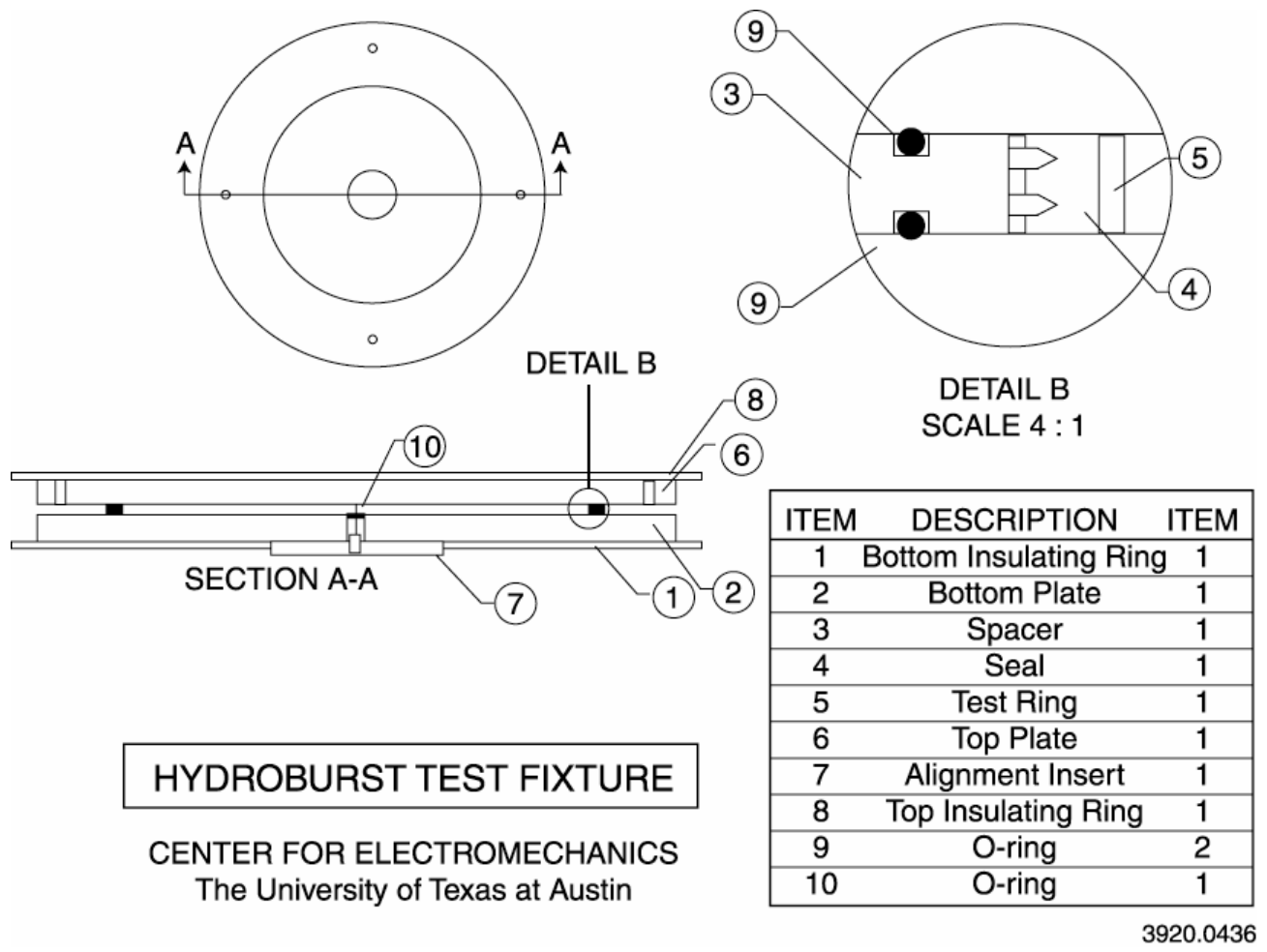

Fig. A-1 - Assembly drawing of the hydroburst test fixture at UT-CEM

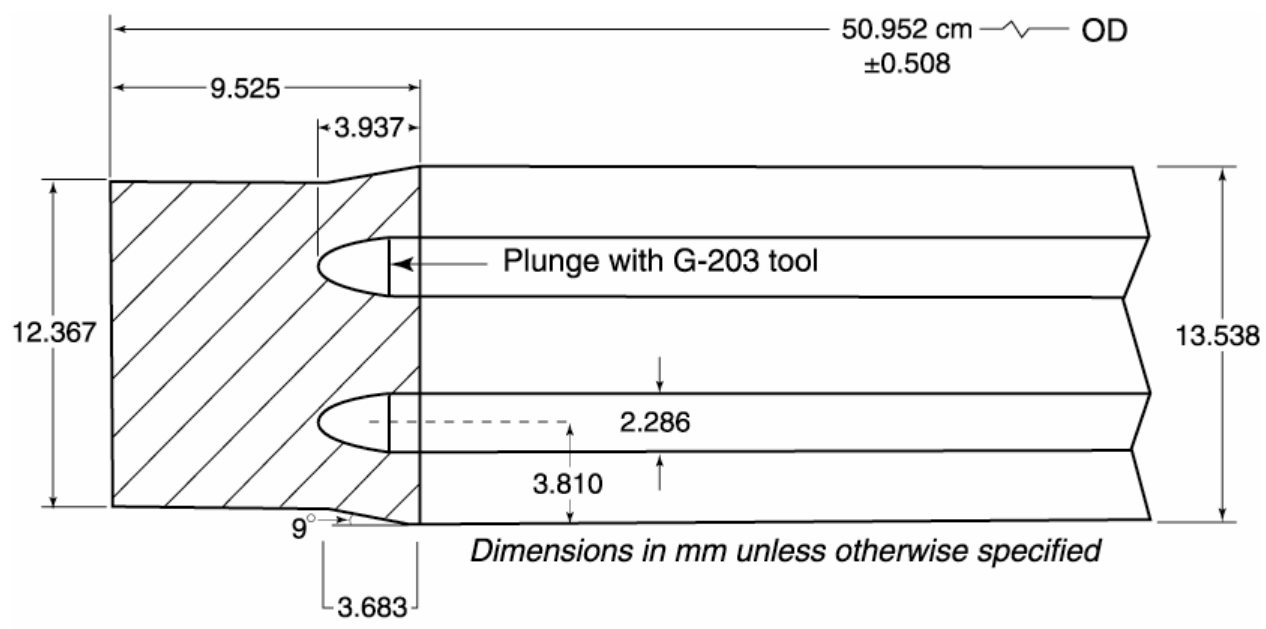

TEI SEALING SYSTEMS

46148 Hwy. 445 - Robert, LA 70455-9745

$504542-8921$ fax 504 542-7513

3920.0437

Fig. A-2 - Details of the seal for hydroburst test fixture at UT-CEM 